\title{
RELATIONSHIP BETWEEN ENTEROBIUS VERMICULARIS INFECTION AND PELVIC INFLAMMATORY DISEASES IN CHILDREN AT SOHAG GOVERNORATE, EGYPT
}

\section{By}

SALAH M. M. HUSSIEN ${ }^{1}$, MOHAMMAD A. A. TAHA ${ }^{1}$ AND EMAN Kh. OMRAN ${ }^{2 *}$ Departments of Parasitology ${ }^{1,2}$, Faculties of Medicine, Al-Azhar University, Assuit Branch ${ }^{1}$, and Sohag University, Sohag ${ }^{2}$, Egypt ( ${ }^{*}$ Correspondence: Dr. E. Omran; moabdallah.1998@hotmail.com; Mobile: 01003077912)

\section{Abstract}

A cohort of children presented with pelvic inflammatory diseases (gastro-intestinal and/or genitourinary surgical conditions) and had concomitant infection with $E$. vermicularis. To find out this relationship, a total of 135 patients suffering from different gastro-intestinal and genitourinary surgical conditions were selected from Departments of Surgery and Gynecology. They were subjected to stool analysis, peri-anal swabs and blood examination mainly for eosinophilia.

The results showed that 26 patients out of $135(19.2 \%)$ had. E. vermicularis with high eosinophilia in 30 cases $(22.2 \%)$. Identification of E. vermicularis by peri-anal swab test in the cohort was successful (16.30\%). Males were more affected than females with ratio 2.2:1 and age mean $7.13 \pm 1.92$. As to residence and housing, rural children with bad housing $(73.08 \% \& 88.46 \%$ respectively) were more affected than those living in urban areas with healthy housing $(26.92 \%$ and $11.54 \%$ respectively ).

Keywords: Egypt, children, Enterobius vermicularis, pelvic inflammatory diseases,

\section{Introduction}

Enterobiasis (threadworm or pinworm disease) is caused by the small nematode $E$. vermicularis. It is probably the most common helminthes to infect humans; prevalence rates of up to $100 \%$ have been recorded in north Western Europe and USA (Cook, 1990). Infection usually occurs by ingestion of eggs by contaminated hands, food, and less commonly water. Local irritation caused by migrating worms (or their eggs) produces the classic symptom that is pruritus ani. Further spread to the environment from finger contamination and autoinfection follows local scratching (Cook, 1990). There is much debate as to whether E. vermicularis causes serious disease in the gastrointestinal tract or is merely a "passenger". Certainly, ectopic infections, seen mainly in females, can cause significant morbidity as well in children aged 5 to 10 years. The most often encountered clinical presentation of E. vermicularis infection is pruritus ani. Occasionally, it presents with enterocolitis, appendicitis and female genital tract infections (Jardine et al, 2006). Rarely, infections have been reported with perianal abscesses (Mahomed et al,
2003). The most common complication is secondary bacterial infection of broken anal skin. Cases colitis secondary to E. vermicularis infection was reported (Macedo et al, 2000). Patients present with pain, rectal bleeding, fever, nausea, vomiting and increased frequency of stools, and in all instances symptoms resolve with anti-parasitic therapy alone (Liu et al, 1995). Scratching of the perineum also makes the female genital organs prone to be infected by the parasite. A majority of cases were caused by Chlamydia trachomatis, but many other organisms were implicated. Ectopic enterobiasis should be considered in the differential diagnosis of pelvic infections of gynecological origin (Craggs et al, 2009). Vulvovaginitis, salpingitis, oophoritis or pelvic inflammatory disease due to E. vermicularis was previously reported (Tandan et al, 2002). Recurrent vaginal enterobiasis despite complete treatment and in absence of gastrointestinal involvement suggested the vagina as a potential reservoir for $E$. vermicularis supported the theory of rare ectopic enterobiasis through the ascending pathway of female genital tract (Kashyap et al, 2014). 
Pin worm was in patients' specimens who underwent surgery for acute appendicitis, with eosinophil and white blood counts elevation predicting preoperative $E$. vermicularis (Akkapulu and Abdullazade, 2015). Besides, Bartholin gland abscess was caused by $E$. vermicularis itself or by secondary bacterial infection (Melahat et al, 2014).

The present study aimed at the evaluation of Enterobius vermicularis as a causative parasitic agent either directly or indirectly among children underwent surgical conditions.

\section{Patients, Materials and Methods}

This study was carried out from June 2014 to February 2015 on 135 children selected from surgery and gynecological departments of Tahta, El-Maragha and Guhina Hospitals at Sohag Governorate. The inclusion criteria having various pelvic inflammatory diseases in the form of anal abscess, appendicitis, anal fistula, bartholin abscess, oophoritis and/or salpingitis. They were subjected to full history taking; age, sex, type of housing, family income and employment with stressed on socioeconomic status and residence. They were 55 female and 80 males with age range 1-10 years. Diagnosis of concomitant E. vermicularis infection was accomplished by detection of adult worms or eggs, or both. Stool examination was done macroscopically and by approval of parents peri-anal Scotch tape 'Cellotape' swab was done (Garcia, 2007), and/or obtained by subungucal deposit by scraping and cutting off finger nails (Requena et al, 2007). Aseptic blood sample was collected and examined for eosinophilia.

Statistical analysis: Data were tabulated and analyzed using STATA intercooled version. Quantitative data student T-test compared means of two groups and compared using Chi square or fisher exact test. Odd ratio was calculated using exact method. $\mathrm{P}$ less than 0.05 were considered significant.

\section{Results}

Of the 135 children, 26 (19.2\%) had $E$. vermicularis and 30 patients had high eosinophilia, 26 infected cases and 4 non-infected cases (Table 1). Regarding the sex and age males were more affected than females with ratio $2.2: 1$ and age mean $(7.13 \pm 1.92$, rang 1 10). The rural children in bad house showed (73.08\% \& 88.46\% respectively) more affected than urban with healthy ones $(26.92 \%$ $\& 11.54 \%$ respectively). The results were given in tables (1, 2, $3 \& 4)$ and figure (1).

Table 1: Distribution of E. Vermicularis in studied cases

\begin{tabular}{|l|c|c|}
\hline \multirow{2}{*}{ Variables } & \multicolumn{2}{|c|}{ Statistical analysis } \\
\hline \multirow{2}{*}{$\begin{array}{l}\text { Enterobius vermicu- } \\
\text { laris }\end{array}$} & Negative 109(80.74\%) & Positive 26(19.26\%) \\
\cline { 2 - 3 } Macroscopic & $121(89.63 \%)$ & $14(10.37 \%)$ \\
\hline Microscopic & $117(86.67 \%)$ & $18(13.33 \%)$ \\
\hline Anal swab \&/or nails & $113(83.70 \%)$ & $22(16.30 \%)$ \\
\hline Eosinophilia & $105(77.77 \%)$ & $30(22.33 \%)$ \\
\hline
\end{tabular}

Table 2: Characteristics of E. vermicularis cases

\begin{tabular}{|l|c|c|c|c|}
\hline \multicolumn{1}{|c|}{ Variables } & Negative $(\mathrm{N}=109)$ & Positive $(\mathrm{N}=26)$ & Total & P value \\
\hline Age in year: Mean (SD) & $6.46 \pm 2.21$ & $7.13 \pm 1.92$ & $6.59 \pm 2.17$ & \\
Age in year: Median (range) & $7(1-10)$ & $7(4-10)$ & $7(1-10)$ & 0.16 \\
\hline Male & $62(56.9 \%)$ & $18(69.2 \%)$ & $80(59.2 \%)$ & \\
Female & $47(43.1 \%)$ & $8(30.8 \%)$ & $55(40.8 \%)$ & $<0.0001$ \\
\hline House: Healthy & $102(93.58 \%)$ & $3(11.54 \%)$ & $105(77.78 \%)$ & \\
House: Unhealthy & $7(6.42 \%)$ & $23(88.46 \%)$ & $30(22.22 \%)$ & $<0.0001$ \\
\hline Income: Low & $9(8.26 \%)$ & $23(88.46 \%)$ & $32(23.70 \%)$ & \\
Income: Middle & $100(91.74 \%)$ & $3(11.54 \%)$ & $103(76.30 \%)$ & $<0.0001$ \\
\hline Family number: mean (SD) & $6.58(2.08)$ & $10.96 \pm 2.67$ & $7.42 \pm 2.80$ & \\
Family number: median (range) & $6(3-14)$ & $11(6-16)$ & $7(3-16)$ & $<0.0001$ \\
\hline Residence: rural & $13(11.93 \%)$ & $19(73.08 \%)$ & $32(23.70 \%)$ & \\
Residence: urban & $96(88.07 \%)$ & $7(26.92 \%)$ & $103(76.30 \%)$ & $<0.0001$ \\
\hline
\end{tabular}


Table 3: Distribution of associated disease in cases

\begin{tabular}{|l|c|}
\hline \multicolumn{1}{|c|}{ Associated disease } & Number (percentage) \\
\hline Anal abscess & $52(38.52 \%)$ \\
Appendicitis & $35(25.93 \%)$ \\
Anal fistula & $24(17.78 \%)$ \\
Bartholin abscess & $18(13.33 \%)$ \\
oophoritis & $5(3.70 \%)$ \\
salpingitis & $1(0.74 \%)$ \\
\hline
\end{tabular}

Fig. 1: Distribution of associated disease in cases

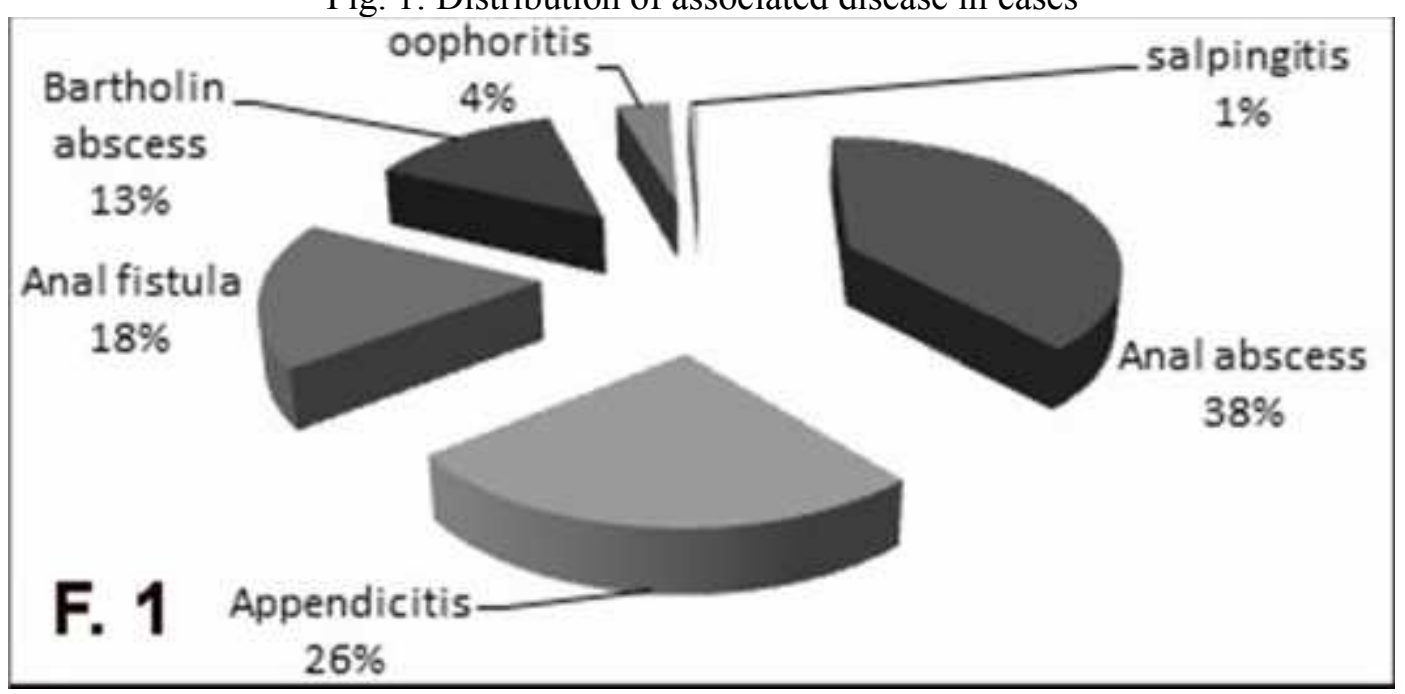

Table 4: Relation between associated disease and E. vermicularis infection.

\begin{tabular}{|c|c|c|c|c|}
\hline \multirow{2}{*}{ Variables } & \multicolumn{2}{|c|}{ E. Vermicularis infection } & \multirow{2}{*}{$\begin{array}{l}\text { Odds ratio } \\
(95 \% \mathrm{CI})\end{array}$} & \multirow{2}{*}{$P$ value } \\
\hline & Negative $(\mathrm{N}=109)$ & Positive $(\mathrm{N}=26)$ & & \\
\hline Anal abscess & $45(41.28 \%)$ & $7(10.00 \%)$ & $0.52(017 .-1.44)$ & 0.18 \\
\hline Appendicitis & $31(28.44 \%)$ & $4(15.38 \%)$ & $0.46(0.11-1.51)$ & 0.17 \\
\hline Anal fistula & $20(18.35 \%)$ & $4(15.38 \%)$ & $0.81(0.18-2.78)$ & 0.72 \\
\hline Bartholin abscess & $10(9.17 \%)$ & $8(30.78 \%)$ & $4.4(1.30-14.21)$ & 0.004 \\
\hline Oophoritis & $2(1.83 \%)$ & $3(11.54 \%)$ & $6.98(1.10-66.16)$ & 0.02 \\
\hline Salpingitis & $1(0.92 \%)$ & 0 & Can't calculated & 0.62 \\
\hline
\end{tabular}

\section{Discussion}

E. vermicularis is a common human intestinal parasite among pre-school and primary school children (Lee et al, 2000). Children are in contact each other more frequently in kindergartens and primary schools than children of other ages, and are also exposed to unsatisfactory sanitary environments (Kim et al, 2003). Despite this high prevalence, enterobiasis was not usually considered to be a serious disease, although ectopic infections, commonly in females, can cause significant morbidity (Russell, 1991) and adults can spread from anal margin to various sites. The local inflammatory response or secondary bacterial infections cause symptoms and clinical presentation (Tandan et al, 2002).

In the present study, of 135 children (110years) $26(19.2 \%)$ had $E$ vermicularis. The relationship between $E$. vermicularis infection and pelvic inflammatory diseases were approved by many authorities, Avolio et al. (1998) reported 13 cases of E. vermicularis presenting as perianal abscess or granuloma, all of which required surgery. Ajao et al. (1997) reported E. vermicularis causing appendicitis in a 14-year-old boy. Presence of the pinworm in the lumen of the appendix may produce the clinical picture of appendicitis. Perforation of the appendix can facilitate the spread of E. vermicularis into the peritoneal cavity. The present results 
showed a high significance between $E$. vermicularis infection and gynaecological problems, which agreed with Kashyap et al. (2014) who reported recurrent vaginal $E$. vermicularis infection. This relation necessitates the diagnostic tests for enterobiasis in adults suffering from these gynecological complaints and its treatment or else there will be recurrence of them.

In the present study, 14 cases were diagnosed by gross examination, microscopical examination of stool samples and peri-anal swab test, four cases by microscopical examination of stool samples only and 8 cases were diagnosed by peri-anal swab only. These results agreed with Armengol et al. (1997) who found that of 1917 Spanish children ages 6 to 10 years $E$. vermicularis was diagnosed in $20 \%$ by using stool analysis and the perianal swab. In the present study, males were more affected than females with age $(7.13 \pm 1.92)$. This agreed with Burkhart et al. (2005) who reported that E. vermicularis was the commonest parasite in the developed world mainly children aged 5 to 10 years. John and Burce (1992) reported that males more affected than females, this agrees with the present results. E. vermicularis infection was found to be prevalent in all ages from 3 to 10 years, and boys were more highly infected than girls (Jae et al, 2005). Inadequate personal hygiene could also increase E. vermicularis risk among children, particularly boys. Other factors including playing on the ground, nail biting, a failure to wash hands before meals, and living in non-apartment dwellings were associated with enterobiasis prevalence (Sung, 2001).

As to the residence and housing, the rural children living in bad house $(73.08 \%$ and $88.46 \%$ respectively) were more affected than urban one in healthy housing $(26.92 \%$ $\& 11.54 \%$ respectively). Family number and income are other factors that cause spread of E. vermicularis infection in these areas as a result of overcrowding, bad general conditions and malnutrition. The repeated health education concerning improving the personal hygiene and regular inspections and mass chemotherapy with the appropriate anthelmintics are essentially required to control enterobiasis (Jae et al, 2005).

Generally speaking, enterobiasis vermicularis is an ancient parasite. Horne (2002) stated that numerous archaeological sites, especially in the arid American southwest, yielded pinworm positive fecal samples dated back 10,000 year. He added that reports of pinworm from the Old World are scarce and evidence of pinworm infection from Roman-occupied (30 BC-AD 395) Egypt. The UNICEF (2000) declared that in Egypt, $56.0 \%$ and $47.0 \%$ of children suffered from intestinal parasites and anemia. Besides, many authors reported enterobiasis mainly among school children such as Awad et al. (1985) in Cairo, Bayoumy et al. (2010) in Nile Delta region, El-Sherbini and Gneidy (2012), in El-Fayoum, El-Sherbini and Abosdera (2013) in Sohag, Hegazy et al. (2014) in El-Behera and Eraky et al. (2014) in Qualyobia as well as in handicapped children (El-Sherbini et al, 2008)

\section{Conclusions}

Enterobius vermicularis must be taken into consideration as a common cause of pelvic inflammatory diseases, especially in high risk areas (rural areas, with unhealthy houses where inhabitants have low socioeconomic status). Although, pinworm infection can affect all people, it is commonest among the children, the institutionalized persons, and household members of persons with pinworm infection. The commonest symptom of pinworms is an itchy rectal area. Symptoms are worse at night during female crawls out of the anus to deposit their eggs. Once a child proved infected, therapy with routine prescription medications should be given with preventive hygiene measures to avoid autoinfection.

\section{Recommendations}

In general, the pinworm infection (enterobiasis or oxyuriasis) causes itching around the anus which can lead to difficulty sleep- 
ing and restlessness. Good hand hygiene is the most effective means of prevention. If pinworm infection occurs again, the patient should be retreated with the same two-dose treatment. The infected person's household contacts and caretakers also should be treated. If pinworm infection continues to occur, the source of the infection should be sought either indoors and/or outdoors and must be treated.

The playmates, schoolmates, close conta- cts outside the home, and the household members should be considered possible sources of pinworm infection. Each infected person should receive the recommended treatment.

\section{Acknowledgment}

Thanks are due to Prof. Dr. Magda M. A. Elnazer, Professor of Parasitology, Faculty of Medicine, Sohag University for her kind revision of this work and her valuable comments.

\section{References}

Ajao, O, Jastaniah, S, Malatini, T, 1997: Enterobius vermicularis (pin worm) causing symptoms of appendicitis. Trop. Doct. 27: 182-3.

Akkapulu, N, Abdullazade, S, 2015: Is Enterobius vermicularis infestation associated with acute appendicitis? Eur. J. Trauma Emerg. Surg. Aug 7. [Epub ahead of print]

Armengol, P, Astolfi, A, Ontiveros, U, 1997: Epidemiology of children's intestinal parasitism in the Guadalquivir Valley. Span. Rev. Esp. Salud. Publ. 71:547-52.

Avolio, L, Avoltini, V, Ceffa, F, 1998: Perianal granuloma caused by Enterobius vermicularis: report of a new observation and review of the literature. J. Paediatr. 132:1055-6.

Awad, RM, Hanallah, RF, Morsy, TA, 1985: The evaluation of some laboratory techniques in the detection of enterobiasis in school children in Egypt. J. Egypt. Soc. Parasitol. 15, 1:305-12

Bayoumy, AM, Mohammed, KA, Shahat, SA, Ghannam, MM, Gazy, Mel S, 2010: Role of parasites among chronic diarrheic patients. J. Egypt. Soc. Parasitol. 40, 3:679-98.

Burkhart, CN, Burkhart, CG, 2005: Assessment of frequency, transmission, and genitourinary complications of enterobiasis (pinworms). Int. J. Dermatol. 44:837-40.

Cook GC, 1990: Parasitic disease in clinical practice. London: Springer-Verlag, Berlin.

Craggs, B, De Waele, E, De Vogelaere, K, Wybo, I, Laubach, M, et al, 2009: Enterobius vermicularis infection with tuboovarian abscess and peritonitis occurring during pregnancy. Surg. Infect. (Larchmt). 10, 6:545-79.

El-Sherbini, GT, Abosdera, MM, 2013: Risk factors associated with intestinal parasitic infections among children. J. Egypt. Soc. Parasitol. 43, 1:287-94.

El-Sherbini, GT, Aboul Noor, MF, Hegazi, MM, 2008: Parasitiosis in handicapped children in an Egyptian blind asylum. J. Egypt. Soc. Parasitol. 38, 1:319-26.

El-Sherbini, GT, Gneidy, MR, 2012: Cockroaches and flies in mechanical transmission of medical important parasites in Khaldyia Village, El-Fayoum, Governorate, Egypt. J. Egypt. Soc. Parasitol. 42, 1:165-74

Eraky, MA, Rashed, SM, Nasr, MS, El-Hamshary, AM, Salah El-Ghannam, A, 2014: Parasitic contamination of commonly consumed fresh leafy vegetables in Benha, Egypt. J. Parasitol. Res. 2014:613960. doi: 10.1155/613960.

García, L S, 2007: Diagnostic Medical Parasitology. $7^{\text {th }}$ ed., USA.

Hegazy, AM, Younis, NT, Aminou, HA, Badr, AM, 2014: Prevalence of intestinal parasites and its impact on nutritional status among preschool children living in Damanhur City, El-Behera Governorate, Egypt. J. Egypt. Soc. Parasitol. 44, 2:517-24.

Horne, PD, 2002: First evidence of enterobiasis in ancient Egypt. J. Parasitol. 88, 5:1019-21.

Jae, HP, Eun, TH, Won, HK, Eun, HS, Sang, MG, et al, 2005: A survey of Enterobius vermicu-laris infection among children on western and southern coastal islands of the Republic of Korea Korean J. Parasitol. 43, 4:129-34.

Jardine, M, Kokai, GK, Dalzell, AM, 2006: Enterobius vermicularis and colitis in Children. J. Pediatr. Gasteroenterol. Nutr. 43:610-2.

John, F, Burce, D, 1992: Perianal abscess in children. Ann. Roy. College of Surgeons, England, 74:385-6.

Kashyap, B, Samantray, JC, Kumar, S, Jhamb, R, Singh, AK, et al, 2014: Recurrent pediatric pinworm infection of the vagina as a potential reservoir for Enterobius vermicularis. J. Helminthol. 88, 3:381-3.

Kim, BJ, Lee, BY, Chung, HK, Lee, YS, Lee, KH, et al, 2003: Egg positive rate of Enterobius vermicularis of primary school children in Geoje Island. Korean J. Parasitol. 41:75-7.

Lee KJ, Lee IY, Im K, 2000: Enterobius vermicularis egg positive rate in a primary school 
in Chungchongnamdo (province) in Korea. Korean J. Parasitol. 38:177-8.

Liu, L, Chi, J, Upton, M, 1995: Eosinophilic colitis associated with larvae of the pin worm Enterobius vermicularis. Lancet 346:410-2.

Macedo, T, Mac-Carty, R, 2000: Eosinophilic ileocolitis secondary to Enterobius vermicu-laris case report. Abdom. Imaging 25:530-2.

Mahomed, AA, MacKenzie, RN, Carson, LS, Jibril, JA, 2003: Enterobius vermicularis and perianal sepsis in children. Pediatr. Surg. Int. 19: 740-2.

Melahat, ED, Tülay, Ö, Fahri, Y, Erol, A, 2014: Enterobius vermicularis: Can it be a possible pathogen in Bartholin gland abscess formation. J. Obstet. Gynaecol. Res. 40, 1:268-70.

Requena, I, Jiménez, Y, Rodríguez, N, Sandoval, M, Alcala, F, et al, 2007: Enterobius vermicularis in preschool children from a suburban area in San Félix, Bolívar State, Venezuela]. Invest. Clin. 48, 3:277-86
Russell, LJ, 1991: The pinworm, Enterobius vermicularis. Prim. Care 18:13-24.

Sung, JF, Lin, RS, Huang, KC, Wang, SY, Lu, YJ, 2001: Pinworm control and risk factors of pinworm infection among primary-school children in Taiwan. Am. J. Trop. Med. Hyg. 65: 558-62.

Tandan, T, Pollard, AJ, Money, DM, Scheifele, DW, 2002: Pelvic inflammatory disease associated with Enterobius vermicularis. Arch. Dis. Child. 86: 439-40.

UNICEF, 2000: Egypt demographic and health survey report, Egypt. 